\title{
Narrow-mouthed water storage vessels and in situ chlorination in a Bolivian community: a simple method to improve drinking water quality
}

\author{
Quick R, Venczel L, Gonzalez O, Mintz E, Highsmith A, Espada A, Damiani E, Bean N, \\ De Hannover R, Tauxe $R$
}

\begin{abstract}
Epidemiologic investigations of the Latin America cholera epidemic have repeatedly implicated untreated drinking water and water touched by hands during storage as important vehicles for disease transmission. To prevent such transmission, we provided a new narrow-mouthed, plastic, water storage vessel and $5 \%$ calcium hypochlorite solution for home disinfection of stored water to a Bolivian Aymara Indian community at risk for cholera. We evaluated acceptance of this intervention and its effect on water quality. Each of 42 families in the study obtained water from a household well; fecal coliform bacteria were found in water from 39 (93\%) of 42 wells and 33 (79\%) of 42 usual water storage vessels. One group of families received the special vessels and chlorine (group A), a second received only the special vessels (group B), and a third served as a control group (group C). Water samples collected every three weeks from group A special vessels had lower geometric mean fecal coliform colony counts $(P<0.0001)$ and lower geometric mean Escherichia coil colony counts $(P<0.0001)$ than water from group $B$ or $C$ vessels. Adequate levels of free chlorine persisted in these vessels for at least $5 \mathrm{hr}$. The special vessels and chlorine solution were well accepted and continued to be used for at least six months. Use of the vessel and chlorine solution produced drinking water from nonpotable sources that met World Health Organization standards for microbiologic quality.
\end{abstract}

The cholera epidemic that began in Peru in January 1991 and swept through Latin America, causing more than $1.000,000$ reported cases and 10.000 deaths, highlighted serious deficiencies in water quality and sanitation in this region. Investigations of cholera outbreaks in Latin America have implicated the consumption of fecally contaminated surface and municipal water sources as a major risk factor for disease transmission. ${ }^{1-5}$ In one investigation, cholera transmission was specifically associated with domestically contaminated water stored in open, widemouthed containers.

The cost of providing potable water to each household and sewage treatment to each community in Latin America has been estimated at $\$ 200$ billion, and these improvements would take at least 12 years to implement (de Macedo CG, Pan American Health Organization, unpublished data). This definitive approach to cholera prevention is not currently feasible. There is an urgent need for preventive measures that are effective, inexpensive, and easily disseminated and implemented.

In November 1992, we initiated a pilot project in El Alto, Bolivia, to determine the feasibility of introducing a new intervention into a community at risk for cholera: calcium hypochlorite solution (a form of chlorine) for disinfection of drinking water stored in the home, and specially designed, plastic, narrow-mouthed, lidded, 20-liter water storage vessels to prevent recontamination of treated drinking water during storage. 


\section{BACKGROUND}

El Alto, Bolivia, is a fast-growing city of approximately 400,000 persons who live on the altiplano above La Paz. Most communities in El Alto lack such basic services as potable water systems, sewage, disposal, and trash removal. In the community of Aymara Indians in which we conducted this investigation, all families obtain water from shallow wells (2-5 meters) that they dig in front of their homes. Most households store drinking water in buckets. All families dispose of human waste on the open ground or in a nearby river. This investigation was conducted during the rainy season from November 1992 through March 1993.

\section{MATERIALS AND METHODS}

Study design. We systematically selected 42 households from a group of 55 community volunteers. These households were randomized into three groups: group A (15 families) received the 20-liter, narrow-mouthed, lidded water vessel (Figure 1 , [Catalog Number 420-812; Toico, Inc., Toledo, $\mathrm{OH}$ ]), referred to as the special vessel) plus the calcium hypochlorite solution, group $B$ (15 families) received the special vessel only. without the disinfection solution, and group C (12 families) served as controls, receiving neither special vessel nor disinfectant.

We conducted a baseline survey of demographic characteristics and water handling and sanitary practices of all participating families. After baseline data were collected, the special vessels were distributed to groups $A$ and $B$, and the calcium hypochlorite solution only to group $A$. Families in groups $A$ and $B$ received instructions about proper use and cleaning of the special vessel. Group A also received education about proper disinfection dose and storage for the chlorine solution. Group C received no education. During the nine-week intervention phase, each family was visited every three weeks for a total of three visits per family. At each visit, the head of household or the person most involved in water handling was interviewed regarding water handling and treatment practices. The field team replenished the chlorine solution during each visit. At the conclusion of the study a meeting was held with participants to solicit opinions about the intervention. Special vessels were then distributed to all control families, and all group B and control families received chlorine and education about its proper use. Three months later, each family was reinterviewed about water handling and treatment practices.

FIGURE 1. Specially-designed, plastic, narrow-mouthed, lidded, 20-liter water storage vessel used in the El Alto study (dimensions: 10' X 10' X 15.5").

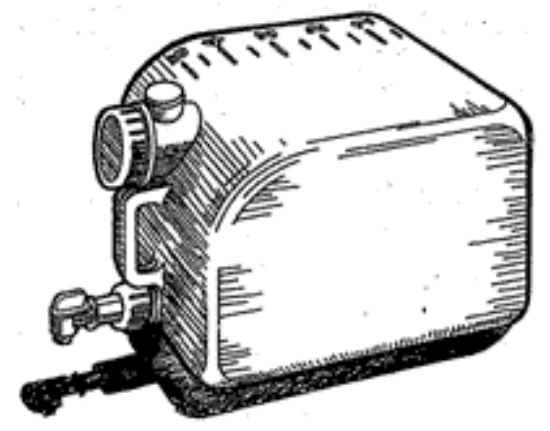


Disinfectant. Calcium hypochlorite solution (0.5\%) was prepared for this study from concentrated (70\% chlorine) high-test hypochlorite $(\mathrm{HTH})$ powder by trained personnel from the University of San Simon in Cochabamba, Bolivia. The solution was packaged in 250-ml opaque containers with a 2-ml screw cap. Participants were instructed to put four capfuls $(8 \mathrm{ml})$ of disinfectant in the 20 -liter vessels each time they tilled them with water. Instructions for disinfectant use were printed in Spanish and Aymara on the disinfectant container, and each family was given a poster with the same instructions to put on the wall.

Evaluation of water quality. Baseline water samples were collected from each household during the baseline survey. including one from the household well (source water) and one from the container used for water storage in the home (original preintervention vessels are referred to as usual vessels). Three rounds of sampling were conducted during household visits in the intervention phase. In the first two rounds, serial water samples were taken from the household water storage vessels (either the special vessel in groups $A$ and $B$ or the usual vessel in group C) at intervals of 0 . 2 , and $4 \mathrm{hr}$ from the time the field team arrived at the household to take the first water sample. In the third round, samples were taken from wells and home storage vessels. During follow-up interviews conducted three months after the intervention phase, water samples were collected only from the special vessels.

The water sample collection method was designed to reflect the water handling practices of the study population. The resident's usual implements were used for water sampling, including their unsterile well water collection bucket and cup used to scoop water, stored in the home. Water temperature was,measured with a digital probe (Hach Company, Loveland. CO), pH with indicator papers (Mikro Insta-chek; Micro Essential Laboratory, Brooklyn, NY), and turbidity with a Jackson turbidimeter (Robens Institute of Health and Safety, University of Surrey, Guildford. United Kingdom), a clear plastic tube that is filled with a water sample through which a black ring at the base of the tube is visualized. Turbidity is expressed as Jackson units, which measure the light path through a suspension that permits the visualization of the black ring; clear water has a value of less than five Jackson units. Free and combined chlorine levels were determined using the $\mathrm{N}, \mathrm{N}$-diethylphenylenediamine (DPD) colorimetric method (Free and Total Chlorine Kit; Hach Co.. Loveland. CO). Water for microbiologic testing was collected in sterile $500-\mathrm{ml}$ polypropylene bottles, which were placed in coolers with frozen ice packs, and transported to the National Institute of Health Laboratories in La Pax for analysis within $24 \mathrm{hr}$ of collection.

Water sample portions of $0.5,5$. and $50 \mathrm{ml}$ were filtered through $0.45-\mu \mathrm{m}$ porosity, 47-mm diameter cellulose fillers (Gelman Sciences. Ann Arbor. MI). Diluting and rinsing were performed using $0.01 \mathrm{M}$ phosphate-buffered saline $(\mathrm{pH} 7.5)$. Each filter was transferred to $60-\mathrm{mm}$ petri plates containing m-FC agar (Difco Laboratories, Detroit, MI), a selective medium for fecal conforms. and incubated at $44.5^{\circ} \mathrm{C}$ for 24 hr. Blue colonies were counted as fecal coliforms. All filters with any visible fecal coliform colonies were transferred to petri plates containing nutrient agar and 4melhy-lumbelliferyl-beta-D-glucuronide. After $4 \mathrm{hr}$ of incubation at $44.5^{\circ} \mathrm{C}$. colonies were illuminated with a handheld ultraviolet light, and fluorescent blue colonies were counted as Escherichia coli.

Bacterial densities $/ 100 \mathrm{ml}$ were calculated from colony counts for sample volumes of 0.5. 5. and $50 \mathrm{ml}$. assuming, that the number of colonies per plate followed a 
Poisson distribution. If the number of colonies on a single filter was in the countable range (10-100). that count was used to estimate the density of fecal coliforms or $E$. coli. If two or more filters had counts in this range, or if all filters with colonies had counts $<10$, the density was estimated by dividing the total number of colonies on those filters by the total volume of sample filtered. If one or more of the filters had counts $<10$, and the others were too numerous to count (TNTC), a maximum likelihood estimator ${ }^{7}$ was used to estimate the colony counts of the sample. If all the counts were TNTC, the concentration was estimated to be twice the upper limit of the countable range $(100)$ of the highest dilution $(0.5 \mathrm{ml})$, or 200 colonies per 0.5 $\mathrm{ml}$. If no colonies were present on the plate, a lower limit of detection of less than or equal to 1 colony per $50 \mathrm{ml}$ sample was assumed and the count was recorded as less than or equal to 2 colonies per $100 \mathrm{ml}$. For calculations of mean bacterial densities, samples whh no detectable fecal coliform or $E$. coli colonies were given a value of two colonies per $100 \mathrm{ml}$.

Geometric means were calculated for estimated bacterial densities of the water tested from wells and vessels from groups A, B, and C for each sampling episode. Multiple linear regression models were used to evaluate the differences between fecal coliform and $E$. coli colony counts in well water samples. Generalized estimating equations ${ }^{1}$ were used to determine the association between the three groups and geometric mean densities of fecal coliforms and $E$. coli colony counts in vessel water.

TABLE 1: Baseline (pre-intervcntion) geometric mean fecal coliform and Escherichia coli colony counts in water samples from household wells and usual household water storage vessels. El Alto. Bolivia. December. 1992*

\begin{tabular}{|c|c|c|c|c|c|c|}
\hline \multicolumn{2}{|c|}{ Water source } & $\begin{array}{c}\text { Study } \\
\text { group }\end{array}$ & $\begin{array}{c}\text { Fecal coliform } \\
\text { (colonies/100 ml) }\end{array}$ & SD & $\begin{array}{c}\text { E. coli } \\
\text { (colonies/100 } \\
\text { ml) }\end{array}$ & SD \\
\hline Well & & A & 106 & \pm 7.0 & 84 & \pm 6.2 \\
\hline Well & & B & 123 & \pm 9.1 & 65 & \pm 11.3 \\
\hline Well & & C & 96 & \pm 9.4 & 78 & \pm 10.7 \\
\hline Storage & vessel & A & 34 & \pm 17.0 & 28 & \pm 14.5 \\
\hline Storage & vessel & B & 114 & \pm 6.5 & 63 & \pm 8.5 \\
\hline Storage & vessel & C & 71 & \pm 10.7 & 39 & \pm 14.6 \\
\hline
\end{tabular}

*Geometric means were calculated from logs of bacterial colony counts and presented in the table as amilogs. Pairwise comparisons between group A (water vessel plus disinfectant), group $B$ (water vessel only), and group C (control) showed no statistically significant differences between any of the three groups for either water source.

\section{RESULTS}

Baseline survey. The mean age of the 42 survey respondents was 34.3 years (range 12-68); 33 (79\%) were female. The 42 households selected included 213 members (mean family size, five persons; range $3-9) ; 109(51 \%)$ were male. The median age of persons in this sample was 14 years (range 2 months to 80 years). Among 84 persons s 18 years of age, 22 (26\%) had no formal education, $36(43 \%)$ 
had less than six years of schooling, and $26(30 \%)$ had more than six years. In the four weeks preceding the survey, $35(18 \%)$ of 199 household members for whom data were available had diarrhea, including 11 (32\%) of 34 less than five years of age.

The water source for all households was a shallow, unlined well dug on their property. All 42 respondents stored water from the well in their homes for drinking. Well water was obtained daily by $39(93 \%)$ respondents; the other three $(7 \%)$ obtained water every other day. Twenty-two (52\%) respondents acknowledged that someone had put their hand into drinking water stored in the house.

Thirty-six (86\%) respondents said they boiled their drinking water. Of these, 13 $(36 \%)$ said they always boiled their water, one (3\%) almost always, and $22(61 \%)$ sometimes. Only one (2\%) respondent had used chlorine as a water disinfectant; 33 (79\%) had no knowledge of, or experience with, chlorine. Thirty-two (76\%) respondents regularly filtered their water through a cloth to remove worms and other visible contaminants.

Water quality. The temperatures of well and container water samples ranged from $7^{\circ} \mathrm{C}$ to $23^{\circ} \mathrm{C}$ (mean $13^{\circ} \mathrm{C}$ ). The water $\mathrm{pH}$ was uniform at 5.5 in all samples throughout the study. Turbidity was less than five Jackson units in $69 \%$ of stored water samples in the baseline water sampling visit, $79 \%$ of vessel samples in the first sampling round of the intervention phase. $90 \%$ in the second round, and $72 \%$ in the final round. Less than $5 \%$ of all samples had turbidity counts $>20$ Jackson units.

No chlorine was detected in baseline stored water samples. In the first sampling round of the intervention phase of the study, the mean free chlorine residual (i.e.. concentration) measured in the special vessels of group A households was $1.6 \mathrm{mg} / \mathrm{L}$ (range $0-3.0$; detectable, chlorine in 14 of 15 [93\%]). In the second round, the mean free chlorine residual was $1.2 \mathrm{mg} / \mathrm{L}$ (range 0-3.4; detectable chlorine in 12 of $14[86 \%]$ ), and in the final round, the mean was $0.7 \mathrm{mg} / \mathrm{L}$ (range $0.1-1.5$; detectable chlorine in $100 \%$ ). Mean free chlorine levels in the special vessel did not change over the 4-5-hr period during which serial water samples were taken on two separate occasions.

Baseline water samples from household wells and from usual water vessels showed no significant differences in fecal coliform and $E$. coli colony counts between groups A, B, and C (Table 1). Fecal coliforms were found in water from 39 (93\%) of 42 wells and $33(79 \%)$ of 42 usual home water vessels. Escherichia coli was isolated from water samples from $37(88 \%)$ of 42 wells and $29(69 \%)$ of 42 usual home water vessels. During the intervention phase, water from group A vessels had substantially lower geometric mean fecal coliform colony counts $(P<0.0001)$ and lower geometric mean $E$. coli colony counts $(P<0.0001)$ than water from group $B$ or $C$ vessels in all three sampling rounds (Table 2). There were no significant differences between fecal coliform or $E$. coli colony counts in water from group $B$ and $C$ vessels. Water quality in $93 \%$ of the samples from group A vessels met World Health Organization microbiological guidelines of less than or equal to $1 E$. coli colony per $100 \mathrm{ml}$ (i.e., no detectable colonies).

During a focus group meeting of study participants at the completion of the intervention phase of the study, all persons expressed satisfaction with the special vessels and the chlorine. Although several persons noted that treated water had a 
chlorine taste, all said they grew accustomed to the taste and continued to use the chlorine. The only change that was suggested for the vessel was to increase its size. All 30 households that received the special vessels at the beginning of the intervention phase were observed to be using them throughout the study. None of the special vessels disappeared or broke during this time.

In the follow-up evaluation three months after completion of the study, water was sampled from the special vessel in 40 of the 42 original households. Water samples had a mean free chlorine residual of $0.5 \mathrm{mg} / \mathrm{L}$ (range $0-3.5) ; 32(73 \%)$ water samples had detectable chlorine. Twenty-four $(60 \%)$ of 40 samples had no detectable fecal coliform colonies, and 31 (78\%) had no detectable $E$. coli colonies. One household was no longer using the special vessel; no water sample was taken from this household. Another family, had moved out of the community and was lost to follow-up.

TABLE 2: Geometric mean fecal coliform and Escherichia coli colony counts per 100 $\mathrm{ml}$ in water samples from household storage vessels for three sampling rounds. El Alto, Bolivia, December 1992-March 1993*

\begin{tabular}{|c|c|c|c|c|c|c|c|}
\hline $\begin{array}{l}\text { Sampling } \\
\text { round }\end{array}$ & $\begin{array}{l}\text { Study } \\
\text { group }\end{array}$ & $\begin{array}{l}\text { Fecal coliform (colonies/100 } \\
\text { ml) }\end{array}$ & SD & $P$ & $\begin{array}{c}\text { E. coli } \\
\text { (colonies/100 } \\
\mathrm{ml} \text { ) }\end{array}$ & SD & $p$ \\
\hline 1 & A & 2.2 & \pm 1.4 & Referent & 2.2 & \pm 1.4 & Referent \\
\hline 1 & B & 43 & +5.5 & $<0.001$ & 25 & +4.7 & $<0.001$ \\
\hline 1 & $C$ & 36 & \pm 17.8 & $<0.001$ & 23 & \pm 13.8 & $<0,001$ \\
\hline 2 & A & 2.4 & +1.8 & Referent & 2.3 & +1.8 & Referent \\
\hline 2 & $B$ & 57 & \pm 19.0 & $<0.001$ & 39 & \pm 17.3 & $<0.001$ \\
\hline 2 & C & 29 & +5.0 & $<0.001$ & 27 & +14.1 & $<0.001$ \\
\hline 3 & A & 2 & 0 & Referent & 2 & 0 & Referent \\
\hline 3 & B & 63 & \pm 14.1 & $<0.001$ & 41 & \pm 11.4 & $<0.001$ \\
\hline 3 & $C$ & 78 & +9.6 & $<0.001$ & 54 & +9.8 & $<0.001$ \\
\hline
\end{tabular}

*Geometric means were calculated from logs of bacterial colony counts and presented in the tables as anilogs. Results of pairwise statistical comparisons between group A (water vessel plus disinfectant), group $B$ (water vessel only, and group $C$ (control) are indicated; the referent is group $A$. None of the pairwise comparisons between groups $B$ and $C$ were statistically sifinificant and these results are not included in the table.

\section{DISCUSSION}

The Latin American cholera epidemic has served as a stark reminder of the inadequacy of the sanitary infrastructure in Central and South America. The high mortality rate from diarrhea among children less than five years old in Latin America (4.2 deaths per thousand children per year $1981-1986^{\circ}$ ) underscores the urgent need for prevention efforts. The inexpensive, simple, and easily disseminated pointof-use water treatment and storage system described here may offer a practical method to protect drinking water supplies in many communities until resources are obtained to provide universal piped, treated water.

This intervention was acceptable to a population of Aymara Indians, who were able to disinfect their drinking water on a sustained basis. Although some decrease in chlorine use and increase in water contamination was noted at the follow-up 
evaluation three months after the study was completed, all but one participant continued to use the container, and most were still using the disinfectant solution. The decrease in use of disinfectant was probably due in pan to inconvenience in obtaining a supply of calcium hypochlorilc solution. After the study ended, the solution was no longer delivered to participants' homes and had to be purchased at a local store.

The narrow-mouthed vessel was developed for several reasons. First, investigations of the cholera outbreak in Latin American ${ }^{2}$ and elsewhere (Swerdlow DL. Centers for Disease Control and Prevention, unpublished data) have implicated drinking water stored in household containers as a risk factor for infection. Second, the hypothesis that water is contaminated during storage is supported by other studies documenting increasing levels of fecal coliforms in drinking water stored over time in widemouthed vessels. ${ }^{10}$ Finally, the use of water vessels with narrow openings has previously been shown to improve water quality in the home, probably, by hindering the introduction of hands into the vessel. ${ }^{11,12}$ In addition to the narrow mouth and spigot, the special vessel had a screw-on lid, giving the further benefits of hindering contamination and decreasing the rate at which chlorine volatilized from treated drinking water. ${ }^{13,14}$ The importance of this feature was shown in a study-recently conducted in Huaricana, Bolivia using a similar intervention; families using chlorine in their usual wide-mouthed household containers did not achieve a reliable improvement in microbiologic quality of their water (Quick RE. unpublished data). The observation that chlorine levels in water in the special vessel were constant over a 4-hr period indicates that chlorine did not volatilize rapidly, nor was it consumed by the plastic itself. The finding that disinfected water in the special vessel did not become recontaminated over time indicated that this narrow-mouthed, lidded vessel enabled households to safely store their water.

Although the special water vessel used in this study was well accepted and used for several months by all but one family, it was by itself not sufficient to improve water quality because the source water used to till the vessels was contaminated. Water disinfection was a critical component. The use of a vessel with a standard volume and a standard disinfectant solution made dosing simple. The narrow range of measured chlorine levels and the consistency of results shows that home drinking water disinfection can be reliably and safely performed even with a relatively uneducated population. Although chlorine treatment gives water a noticeable taste, this did not impede its use among study participants who consistently produced and consumed bacteriologically acceptable drinking water. Another study, however, documented that noticeable taste, fear of toxicity. and the belief that water treatment is not necessary can be impediments to treating household water with chlorine. ${ }^{15}$ In addition to using a simple dosing strategy, adequate promotion and education are essential to successful use of chlorine disinfectant.

Although the concentrated HTH powder used to make calcium hypochlorite solution for this study is convenient to transport, it has two serious drawbacks. First, it is caustic and therefore hazardous to transport and to reconstitute into solution if not handled properly. Second, because it is not produced in most developing countries, HTH powder must be purchased and imported, which increases the expense and the risk of an interruption of disinfectant supply. Inexpensive alternatives to HTH exist. For example, disinfectant solution for water can be produced in rural and periurban communities by available appropriate technology (e.g.. Sanilec On-Site Hypochlorite Generator; Eitech International Corp., Sugarland. TX, and MIOX System: Los Alamos 
Technical Associates. Inc., Albuquerque, NM). which permits self-sufficiency in disinfectant production ${ }^{12}$ (Loret $\mathrm{P}$, unpublished data). The cost of producing disinfectant has been estimated at $\$ 0.25$ per family per year. ${ }^{12,16}$

Two indicators of disinfection efficiency, fecal coliforms and $E$. coli, were chosen for this study. Fecal coliforms include $E$. coli. which is presumed to be exclusively fecal in origin, and some species of Klebsiella and Citrohacter, which have nonfecal sources. Little is known about the impact of fecal coliforms on drinking water quality when there is a mixture of fecal and nonfecal organisms. ${ }^{17}$ Total and fecal coliforms have been used as indicators of water treatment efficacy for many years, but other organisms such as $E$. coli, coliphage, and enterococci may also be appropriate. ${ }^{18,19}$ Thus, both fecal coliforms and E. coli were included in this study to compare their prevalence in natural waters in Bolivia and their survival in disinfected water. Eschenchia coli may be a more suitable indicator of water contamination and disinfection effectiveness for this study site because its presence in water samples and inactivation kinetics are similar to fecal coliforms and it is a more specific indicator of human fecal contamination.

This study had several limitations. The participants were from a self-selected group of community residents, who may have been more motivated to comply with study requirements than the general population. Although the findings of this study cannot be readily generalized, they demonstrate what a motivated community can accomplish. Attrition was low, in contrast to a study of household chlorination in Brazil in which nine (36\%) of 25 participants dropped out. ${ }^{15}$ The problem of attrition would be best addressed through the application of social marketing techniques and improvement of disinfectant distribution to make its use more convenient (e.g., home delivery). Study participants may have also exhibited the Hawthorne effect; that is, their performance was improved simply by the process of being observed. ${ }^{20}$ However, most participants continued to use chlorine after the end of the study. This study also had the potential for information bias. Because the water vessels are a tangible presence, field workers could not be blinded to intervention and control groups, raising the possibility of interviewers biasing results toward a positive impact of the intervention. This risk was reduced by the use of chlorine measurement to provide objective verification of compliance. The virtual absence of bacteria in intervention group water eliminated bias in counting colonies.

In conclusion, this study demonstrated that Aymara Indian families in a periurban area of Bolivia were able to use successfully a simple, inexpensive system of water treatment and storage to greatly improve their drinking water quality. The special water vessel was well accepted and durable. A reliable, sustainable system of production, distribution, and marketing of disinfectant is critical to achieving the goal of community self-sufficiency in safe water production. The efficacy of this water treatment and storage system in preventing diarrheal diseases was not tested in this pilot study because we first wanted to evaluate the acceptability and effectiveness of the intervention in improving water quality; the next phase, a study of the effectiveness of the intervention in preventing diarrhea, is in progress. In acute emergency settings, people can boil their water to prevent disease transmission. Universal, piped, treated water and sewage treatment represent the long-term and definitive solution to waterborne disease transmission, but the high cost of such an intervention will slow progress in providing these services. Therefore, point-of-use disinfection with a safe water storage vessel may offer promise as a sustainable 
medium-term intervention to improve water quality and prevent disease transmission in many parts of the developing world.

Acknowledgments: We are grateful to Carmen Revollo, Victor Diaz, and Patricia Machaca for diligent and reliable work in the field and the laboratory. For technical advice, we are grateful to Drs. Mark Sobsey and Christine Moe. For invaluable assistance in surmounting administrative and logistical hurdles, we thank Dr. Alvaro Munoz Reyes.

Financial support: This work was supported in part by a Prevention Research and Development Grant from the Centers for Disease Control and Prevention.

\section{REFERENCES}

1. Rics AA. Vuaia DJ, Beingolea L. Palacios JM, Vasquez E. Wells JG. Baca NG. Swerdlow DL. Pollack M. Bean NH. Seminario L, Tauxe RV, 1992. Cholera in Piura. Peru: a modern urban epidemic. J Infect Dis 166: 1429-1433.

2. Swerdlow D, Mintz E. Rodriguez M. Tejada E. Ocampo C. Espejo L. Greene KD, Saldana W. Seminario L, Tauxe RV. Wells JG. Bean NH. Ries AA. Pollack M. Vertiz B, Blake PA. 1992. Transmission of epidemic cholera in Trujillo, Peru: lessons for a continent at risk. Lancet 340: 28-32.

3. Weber JT. Mintz ED. Canizares R, Semiglia A. Gomez I, Sempertegui R. Davila A. Greene KD, Puhr ND, Cumeron DN. Tenover FC, Barrett TJ, Bean NH, Ivey C. Tauxe RV, Blake PA, 1994. Epidemic cholera in Ecuador: antimicrobial resistance and transmission by water and food. Epidemiol Infect 112:1-11.

4. Mujica 0, Quick RE, Palacios AM. Beingolea L, Vargas R. Moreno D. Barret TJ. Bean $\mathrm{NH}$, Seminario L, Tauxe RV, 1994. Epidemic cholera in the Amazon: the role of produce in disease risk and prevention. J Infect Dis 169: 1381-1384.

5. Cardenas V. Saad C. Varona M. Linero M. 1993. Waterborne cholera in JRiohacha. Colombia. 1992. Bull Pan Am Health Organ 27: 313-330.

6. Mates A, Shaffer M. 3989. Membrane filtration differentiation. of $E$. coli from coliforms in the examination of water. J Appi Bacterial 67: 343-346.

7. Haas CN. Heller B, 1988. Averaging of TNTC counts; Appi Environ Microbiol 54: 2069-2072.

8. Zeger SL, Liang KY. 1986. Longitudinal data analysis for discrete and continuous outcomes. Biometrics 42: 121-130.

9. Marlines J, Phillips M. Feachem RGA. 1993. Diarrheal diseases. Jamison DT. Mosley WH. Measham AR, Bobadilla JL. eds. Disease Control Priorities in Developing Countries. New York: Oxford University Press. 91-116. 
10. Han AM,Oo KN, Midorikawa Y, Shwe S, 1989. Contamination of .drinking water during collection and storage. Trop Geogr Med 41: 138-140

11. Deb BC. Sircar BK. Sengupta PG, De SP, Mondal SK. Gupta DN Saha NC, Ghosh S, Mitra U, Pal SC, 1986. Studies on interventions to prevent eltor cholera transmission in urban slums. Bull World Health Organ 64: 127-131.

12. Mintz ED, Reiff FM. Tauxe RV, 1995. Safe water treatment and storage in the home: a practical new strategy to prevent waterbome disease. JAMA 273: 948-953.

13. Pinfold JV, 1990. Faecal contamination of water and fingertip-rinses as a method for evaluating the effect of low-cost water supply and sanitation activities on faecooral disease transmission. II. A hygiene intervention study in rural north-east Thailand. Epidemiol Infect 105: 377-389.

14. Hammad ZH. Dirar HA, 1982. Microbiological examination of sebeel water. Appi Environ Microbiol 43: 1238-1243.

15. Kirchhoff LV, McClelland KE, Pinho MDC, Araujo JG, De Sousa MA, Guerrant RL, 1985. Feasibility and efficacy of in-home water chlorination in rural North-eastern Brazil. J Hyg (Camb) 94: 173-180.

16. Wilt VM, Reiff FM, 1993. La Desinfeccion del Agua a Nivel Cascro en Zonas Urbanas Margmates y Rurales. Serie Ambiental No. 13. Washington. DC: Pan American Health Organization

17. Barrell RAE, Rowland MGM, 1979. The relationship between rainfall and well water pollution in a West African (Gambian) village. J Hyg (Camb) 83: 143-150.

18. Cabelli VJ, Dufour AP, McCabe LJ, Levine MA, 1982. Swimming associated gastroenteritis and water quality. Am J Epidemiol 115: 606-616.

19. Moe CL, Sobsey MD, Samsa GP, Mesolo V, 1991. Bacterial indicators of risk of diarrheal disease from drinking-water in the Phillipines. Bull World Health Organ 69: 305-317.

20. Adair J, 1984. The Hawthorne effect: a reconsideration of the methodological artifact. J Appi Psychol 69: 334-345.

\section{Suggested citation:}

Quick R, Venczel L, Gonzalez O, Mintz E, Highsmith A, Espada A, Damiani E, Bean N, De Hannover R, Tauxe R. Narrow-mouthed water storage vessels and in situ chlorination in a Bolivian community: a simple method to improve drinking water quality. American Journal of Tropical Medicine and Hygiene 1996; 54: 511-516. 